\title{
Rukmini Pande, Squee from the Margins: Fandom and Race
}

\section{Review by Caron Wildy}

Rukmini Pande. Squee from the Margins: Fandom and Race. University of lowa Press, 2018.

With Squee from the Margins: Fandom and Race, Rukmini Pande explores fan communities, or fandoms, as postcolonial cybercultural spaces that have emerged and evolved along with the expansion of online communities, with a specific focus on how these communities make space for members who do not adhere to perceptions of popular culture fans as predominantly white, male, and located in the West. Pande provides a smart, focused exploration of fans who do not fit this mold and how these fans engage with texts and create fan works that expand on and reconstitute characters and narratives from canonical texts.

Squee reads like a response to the emerging notion that "fandom is broken", an idea first suggested by film critic Devin Faraci in a 2016 essay. This brokenness is evident in "review bombing" campaigns launched by right-wing segments of fandoms against films that promote diverse representation, in front of and behind the camera, or fail to align with specific, traditional views of a franchise's canon. With review bombing campaigns, "fans" from the aforementioned segments of fandoms flood review aggregator sites, such as Rotten Tomatoes, with negative prerelease reviews in hopes of damaging ticket sales before a film's release. These campaigns are so common that the review bombing of Anna Bolden and Ryan Fleck's Captain Marvel in early 2019 was just another in a string of campaigns that extend back to 2016. In February of 2018, members of the alt-right aligned Facebook group "Down With Disney's Treatment of Franchises and its Fanboys" launched a review bombing campaign against Ryan Coogler's Black Panther for its presentation of a predominantly Black cast. Black Panther eventually grossed $\$ 1.3$ billion at the box office and the highest amount of pre-sales for a Marvel Studios release at the time. In December 2017, the "Down with Disney" group launched a similar campaign against Rian Johnson's Star Wars: Episode VIII The Last Jedi for elevating female characters at the expense of incompetent male characters. Pre-sales for The Last Jedi generated so much traffic on ticket sales site Fandango that the site crashed in October 2017. The film went on to earn $\$ 1.3$ billion globally.

One year before the Last Jedi campaign, a contingent of Ghostbusters fans launched a "downvote campaign" against Paul Feig's 2016 reboot and its all-female roster of Ghostbusters. This downvote campaign was a protoreview bombing where presumably misogynistic fans used YouTube's dislike feature to register 13,800 dislikes of the film's trailer in one day. Fans also attacked the film's cast on social media. In the case of actor Leslie Jones, the attacks, which targeted her for both being a Black woman playing a stereotype and portraying a traditionally male role, were so vicious that Jones temporarily deleted her Twitter account in July of 2016. The review bombings and social media attacks were part of a pattern of online harassment, or trolling, that defined some of the most extreme fan activity of the decade.

In the wake of review bombings and increasing hostilities between fans and creators, media critics, scholars, and fans are confronting emerging realities of how fans interact with each other, creators, and texts. The racial demographics of fandoms, however, were often overlooked when examining the driving forces behind fandoms and how fandoms engage with creators and texts, respond to diverse representation, and welcome diverse voices. Pande, an assistant professor at the Jindal Global Law School at O.P. Jindal Global University, provides a timely and necessary advocacy for applying the lens of race to scholarly investigation of fandoms that is invaluable to students and scholars of media, cultural, and fan studies. In examining fan works and online fandoms, Pande, whose research explores intersectional identity and popular culture, traces a broad history of nonwhite fans in 
popular multimedia fandoms -including Star Wars and Final Fantasy-from the touchstone of Racefail '09. Pande wisely builds on this history, and the work of Rebecca Wanzo, by urging scholars to expand their theoretical frameworks for examining fandom beyond the cornerstone of whiteness and to reframe these explorations by more carefully considering fans' racial identities.

Pande's goal is to expand the focus of fan studies and scholarship to include more nuanced discussions of race as critical to fan engagement with texts and fandoms. To this admirable end, she shines a light on the obstacles to engagement and enjoyment that nonwhite fans have faced as part of predominantly white fandoms. As part of this consideration, Pande examines fan activism and efforts of fans to use texts and fan works to address real-world social issues and build movements that dismantle hegemonic ideologies and interrogate creators who willingly, or unwillingly, ascribe to such ideologies in their work. This examination is a clever springboard for Pande's efforts to reaffirm the need for nuanced academic exploration of race as an axis of fan identity, particularly in its disruption of the idea that fandoms and pop culture texts are nigh-utopian bastions of progressive liberalism and communitarian resistance to hegemony.

After building a strong case for scholarly consideration of racial identity among fandoms, Pande takes an awkward turn in her concluding chapter, where she explores kink memes in fan fiction. Kink memes are works of fan fiction that place characters from canonical texts in romantic or sexual relationships that contradict, expand on, or recontextualize canon characterizations and relationships. Pande briefly examines formations of kink memes within Supernatural (2005-2020), Glee (2009-2015), and Star Trek (2009) fandoms, but this examination may have been more impactful with a deep dive into the kink meme generated by any one of these fandoms instead of all three. As a concluding chapter, its positioning also seems a touch questionable, if only because this chapter could have functioned as an intriguing hook to draw readers into her arguments for race as a consideration in fan studies by highlighting the misconceptions of fan fiction like kink meme as free from the influence of the exclusionary qualities that surface in canon texts that attract mainstream audiences.

Despite the somewhat jarring shift to the kink meme exploration, Squee is perceptive, intriguing, and timely. By bringing attention to race as a core component of fan identity, Pande challenges media, cultural, and fan studies scholars to reflect on the biases that inform and handicap their research. Pande's challenge is noteworthy, albeit one rife with the potential to raise the ire of scholars deeply invested in the view of fandoms as monocultural and homogenous. Pande raises essential questions about fan studies that may generate uncomfortable answers, but these questions are necessary to move the field forward and prepare its scholars to better engage global fan communities that frequently challenge the perception of fans as white, male, and situated in the West. Squee is also a necessary reminder of the interdisciplinarity at the core of fan studies, a field that can touch on myriad disciplines such as sociology, linguistics, media studies, and cultural studies. Squee is even more necessary as a beacon that may empower media critics, scholars, and fans to predict and possibly prevent future occurrences of the review bombings and trolling that have adversely impacted fan engagement for fans of all racial identities for far too long.

\section{Works Cited}

"Black Panther (2018)." Box Office Mojo, www.boxofficemojo.com/movies/?id=marvel2017b.htm.

Faraci, Devin. "Fandom Is Broken." Birth.Movies.Death., 31 May 2016, birthmoviesdeath.com/2016/05/30/fandomis-broken.

Griner, David. "Reactions to the All-Female Ghostbusters Trailer Prove It'll Be the Most Polarizing Movie of the Year." Adweek, Adweek, 3 Mar. 2016, adweek.com/creativity/reactions-all-female-ghostbusters-trailer-prove-itll-bemost-polarizing-movie-year-169984/.

Salam, Maya. "Trolls Tried to Sink 'Captain Marvel.' She Triumphed." The New York Times, 15 Mar. 2019, nytimes.com/2019/03/15/arts/captain-marvel-trolls.html. 
"Star Wars: The Last Jedi (2017)." Box Office Mojo, boxofficemojo.com/movies/?id=starwars8.htm.

\section{Cite this Essay}

Wildy, Caron. "Rukmini Pande, Squee from the Margins: Fandom and Race." Rhizomes: Cultural Studies in Emerging Knowledge, no. 35, 2019, doi:10.20415/rhiz/035.r06

RHIZOMES ISSN 1555-9998 $\star 230$ East Hall Bowling Green State University Bowling Green, OH 43403

Editors: Ellen Berry and Carol Siegel. Reviews editor: Craig J. Saper. Technical editor: Helen J Burgess 